
Endocrinology, Lyon, 26 April 2003

\title{
Tissue-specific Cushing's syndrome, 11ß-hydroxysteroid dehydrogenases and the redefinition of corticosteroid hormone action
}

\author{
Paul M Stewart \\ Division of Medical Sciences, University of Birmingham, Queen Elizabeth Hospital, Birmingham B15 2TH, UK \\ (Correspondence should be addressed to P M Stewart; Email: P.M.Stewart@bham.ac.uk)
}

\begin{abstract}

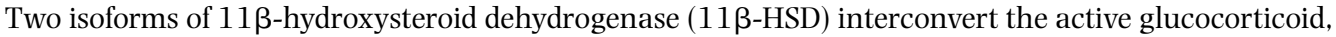
cortisol, and inactive cortisone. 11 $\beta$-HSD1 acts predominantly as an oxo-reductase in vivo using $\mathrm{NADP}(\mathrm{H})$ as a cofactor to generate cortisol. In contrast, 11 -HSD2 is a NAD-dependent dehydrogenase inactivating cortisol to cortisone, thereby protecting the mineralocorticoid receptor from occupation by cortisol. In peripheral tissues, both enzymes serve to control the availability of cortisol to bind to corticosteroid receptors. $11 \beta-H S D 2$ protects the mineralocorticoid receptor from cortisol excess; mutations in the HSD11B2 gene explain an inherited form of hypertension, the syndrome of 'apparent mineralocorticoid excess', in which 'Cushing's disease of the kidney' results in cortisol-mediated mineralocorticoid excess. Inhibition of 11ß-HSD2 explains the mineralocorticoid excess state seen following liquorice ingestion and more subtle defects in enzyme expression might be involved in the pathogenesis of 'essential' hypertension.

$11 \beta$-HSD1 by generating cortisol in an autocrine fashion facilitates glucocorticoid receptor-mediated action in key peripheral tissues including liver, adipose tissue, bone and the eye. 'Cushing's disease of the omentum' has been proposed as an underlying mechanism in the pathogenesis of central obesity and raises the exciting possibility of selective $11 \beta$-HSD1 inhibition as a novel therapy for patients with the metabolic syndrome.

'Pre-receptor' metabolism of cortisol via 11ß-HSD isozymes is an important facet of corticosteroid hormone action. Aberrant expression of these isozymes is involved in the pathogenesis of diverse human diseases including hypertension, insulin resistance and obesity. Modulation of enzyme activity may offer a future therapeutic approach to treating these diseases whilst circumventing the endocrine consequences of glucocorticoid excess or deficiency.
\end{abstract}

European Journal of Endocrinology 149 163-168

\section{Introduction}

Harvey Cushing's elegant description of bilateral adrenal hyperplasia in association with pituitary basophilia did far more than define a new disease entity, 'Cushing's disease'. His meticulous depiction of the clinical features of the disease that bears his name informed us of the diverse and deleterious effects of cortisol excess. We now appreciate that Cushing's syndrome results in hypertension in $>90 \%$ of cases, visceral obesity in $80 \%$ of cases and osteoporosis in $50 \%$ of cases. In many cases these features are reversible on correcting the cause - proof beyond doubt of the consequences of circulating cortisol excess. In subsequent years investigators have attempted to apply these findings to broader populations - subjects with 'essential' hypertension, 'simple' obesity and idiopathic osteoporosis but have drawn a blank. Endogenous Cushing's syndrome is excessively rare (incidence approximately one per million) and circulating cortisol concentrations are invariably normal (if not slightly reduced) in the above disease processes. Our emphasis has been to identify factors that might regulate corticosteroid hormone action at a tissue-specific level independent of these normal circulating concentrations. Here the metabolism of cortisol by isozymes of $11 \beta$ hydroxysteroid dehydrogenase (11ß-HSD) is of great relevance.

\section{Cortisol metabolism and $11 \beta$-HSDs}

The metabolism of cortisol is both complex and tissue dependent, but a major pathway is the interconversion 
of active cortisol to inactive cortisone by $11 \beta$-HSD. To date, two isoforms of $11 \beta$-HSD have been extensively characterised. 11 3 -HSD1 was originally isolated from liver (1) but is also expressed in adipose tissue, gonad, brain, bone, ocular tissues and muscle (2). The HSD11B1 gene is located on chromosome 1q32.2, is over $30 \mathrm{~kb}$ in length, principally due to the length of intron $4(25 \mathrm{~kb})$, comprises 6 exons and encodes a $34 \mathrm{kDa}$ protein. The enzyme resides within the endoplasmic reticulum and activity is $\mathrm{NADP}(\mathrm{H})$ dependent. Activity is bi-directional possessing both dehydrogenase (cortisol to cortisone) and reductase (cortisone to cortisol) activity but in vivo in intact cells the enzyme appears to function almost exclusively as a reductase $(3,4)$. As a consequence the enzyme facilitates glucocorticoid receptor (GR)-mediated hormone action in tissues where it is expressed.

By contrast, 11ß-HSD2 utilises NAD to inactivate cortisol to cortisone. The HSD11B2 gene is found on chromosome $16 \mathrm{q} 22$, is $\sim 6.2 \mathrm{~kb}$ in length, comprising 5 exons, and encoding a $44 \mathrm{kDa}$ protein. The enzyme is located to the endoplasmic reticulum although perinuclear localisation has been demonstrated. $11 \beta$-HSD1 and $11 \beta$-HSD 2 share only $14 \%$ sequence homology. In normal adult tissues, 11 -HSD2 is expressed in mineralocorticoid receptor (MR)-rich tissues, kidney, colon and salivary gland (5) where it serves to protect the MR from cortisol excess. In vitro the MR has similar affinity for cortisol and its cognate ligand, aldosterone; aldosterone occupies the MR in vivo only when cortisol is inactivated to cortisone in an autocrine fashion by $11 \beta$-HSD 2 .

$11 \beta$-HSD2 is also expressed in many fetal tissues including the placenta (6). Recent data also suggest high levels of expression in some malignant tissues. At these sites $11 \beta$-HSD2 appears to protect the GR rather than the MR.

Cortisol secretion and metabolism are intricately linked and tightly controlled in order to maintain circulating cortisol levels. With increasing metabolic clearance of cortisol there is an associated increase in adrenocorticotrophin (ACTH) secretion and cortisol production in order to maintain circulating levels. The metabolism of cortisol therefore plays a critical role in determining the activity of the hypothalamo-pituitary-adrenal (HPA) axis. Following interconversion of cortisol and cortisone, A ring reduction by $5 \alpha / 5 \beta$-reductases and $3 \alpha$-hydroxysteroid dehydrogenase yields tetrahydrocortisone (THE), $5 \beta$ tetrahydrocortisol (THF) and $5 \alpha$-tetrahydrocortisol (allo-THF). The ratio of urinary free cortisol (UFF) to urinary free cortisone (UFE) is an accurate measure of renal 11ß-HSD2 activity (7). Abnormalities in this ratio can then be reflected in the urinary THF + allo-THF:THE ratio but if the UFF:UFE ratio is normal any change in the THF + allo-THF:THE ratio indicates an alteration in 11ß-HSD1 activity (7) (Fig. 1).

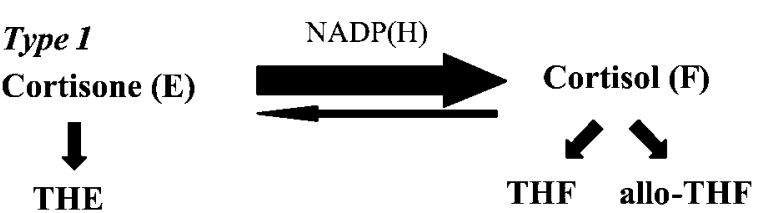

Ratio THF + allo-THF:THE

Type 2

Cortisol (F)

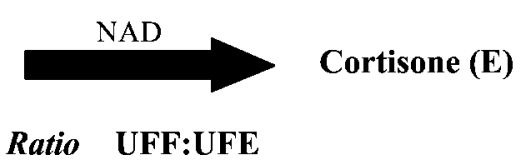

Figure 1 Two isoforms of $11 \beta$-hydroxysteroid dehydrogenase catalyse the interconversion of cortisol $(F)$ to cortisone $(E)$. Type 1, in vivo, functions almost exclusively as a reductase generating cortisol from inactive cortisone. Type 2 functions as a dehydrogenase inactivating cortisol and thus protecting the mineralocorticoid receptor.

\section{1 $\beta$-HSDs and human disease}

\section{Apparent mineralocorticoid excess and hypertension}

Apparent mineralocorticoid excess (AME) is an inherited form of hypertension. The prevalence of the condition is unknown but is likely to be rare as less than 100 cases have been reported $(8,9)$. Presentation is usually in neonatal life or childhood with low birth weight, failure to thrive, hypertension and hypokalaemia. Hypokalaemia may result in arrhythmias, nephrogenic diabetes insipidus and rhabdomyolysis. Both plasma renin activity and aldosterone levels are suppressed in all cases of AME and the diagnosis is made by a urinary cortisol metabolite analysis with an increase in the UFF:UFE and THF + allo-THF:THE ratios. The half-life of cortisol is prolonged in AME as a consequence of the inhibition of cortisol-to-cortisone conversion. As a compensatory mechanism, endogenous cortisol secretion rate is reduced so as to maintain normal circulating corticosteroid levels. A milder variant of AME may present in later life. Again, patients are hypertensive with hypokalaemia but the THF + allo-THF:THE ratio is only mildly abnormal. In all cases cortisol is the offending mineralocorticoid because of failure to inactivate cortisol to cortisone at the site of the MR and the ensuing 'Cushing's disease of the kidney'.

AME is inherited as an autosomal recessive trait and is explained on the basis of mutations in the HSD11B2 gene. There is a close correlation between genotype and phenotype - inactivating mutations result in severe, often fatal hypertension with presentation in early neonatal life, whilst mutations that encode cDNAs with residual enzyme activity present later in life with a milder phenotype (10). A summary of 


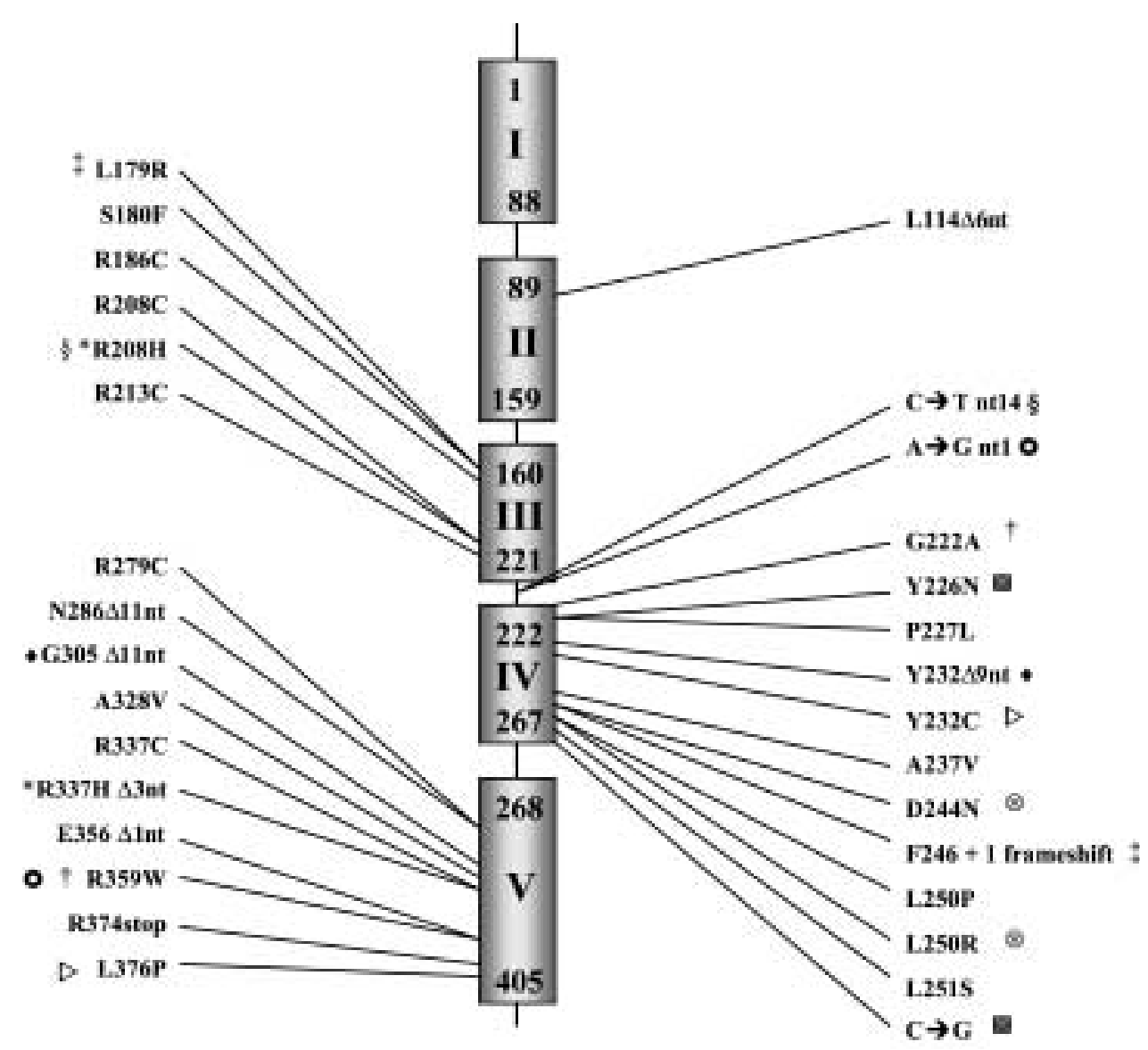

Figure 2 Mutations within the HSD11B2 gene giving rise to the syndrome of 'apparent mineralocorticoid excess' (paired symbols represent compound heterozygotes).

their location within the HSD11B2 gene is shown in Fig. 2.

Dexamethasone is not metabolised by $11 \beta$-HSD2 and, by suppressing cortisol secretion rate, has been used therapeutically in affected cases. Control of hypertension can be difficult and multiple anti-hypertensive agents are often needed.

These studies have raised the important question as to the role of $11 \beta-H S D 2$ in patients with 'essential hypertension'. The prevalence of AME is unknown but milder cases are reported together with heterozygous HSD11B2 mutations presenting as 'essential hypertension' (11).

Association and linkage studies using CA nucleotide repeats and single nucleotide polymorphisms close to or within the HSD11B2 gene have failed to demonstrate any association between HSD11B2 and essential hypertension per se, but the studies were not powered to exclude a minor effect. Association with hypertensive intermediate or sub-phenotypes including nephropathy and salt sensitivity has been demonstrated however and linked functionally to reduced renal 11ß-HSD2 expression $(12,13)$.

\section{Liquorice ingestion}

The active component of liquorice is glycyrrhetinic acid (GE) and the use of liquorice as an anti-indigestion remedy ultimately led to the use of a derivative of GE, $18 \beta$-glycyrrhetinic acid, in the development of the anti-ulcer drug, carbenoxolone. The mineralocorticoid side effects of both liquorice and carbenoxolone are well documented and include oedema, dyspnoea and hypertension with hypokalaemia. It was initially thought that GE and carbenoxolone were direct agonists upon the MR, but our studies, endorsed by others, established that these compounds inhibit $11 \beta$ HSD2 to account for their mineralocorticoid effects. Treatment with spironolactone ameliorates these side effects. The clinical picture is one of an acquired form of AME as a result of cortisol-induced mineralocorticoid excess (14).

\section{Ectopic ACTH syndrome}

Patients with Cushing's syndrome secondary to ectopic ACTH production invariably develop hypertension with 
hypokalaemic alkalosis due to a state of mineralocorticoid excess. This is explained on the basis of exceedingly high cortisol concentrations that saturate 11ß-HSD2. The very high levels of urinary free cortisone indicate that the enzyme is performing at its maximal level, but nevertheless is insufficient to metabolise the excessive quantities of cortisol. Cortisol spills over to act on the MR to cause an AME phenotype $(7,15)$.

\section{Cortisone reductase deficiency and polycystic ovary syndrome}

Cortisone reductase deficiency (CRD) is in many ways the exact opposite of AME. Patients display a defect in the conversion of cortisone to cortisol, suggesting inhibition of 11 oxo-reductase activity and therefore, by implication, inhibition of $11 \beta-H S D 1$. Less than 10 cases have been described, with one exception all are female (16-18). Aberrant cortisone metabolism increases the metabolic clearance rate of cortisol with activation of the hypothalamo-pituitary-adrenal axis and increased ACTH secretion to maintain normal circulating cortisol concentrations but at the expense of adrenal androgen excess. Therefore, patients have presented with a polycystic ovary syndrome (PCOS)-like phenotype with hirsutism, oligoamenorrhoea and infertility. Urinary tetrahydro-metabolites show almost exclusively THE with little or no detectable THF or allo-THF (THF + allo-THF:THE ratio <0.05). Further studies have also shown impaired cortisol generation following an oral dose of cortisone acetate (16), data that implicate a defect in $11 \beta$-HSD1 as being causative in the syndrome of CRD. Recent in-house data suggest that CRD might represent a digenic disease, caused by mutations in HSD11B1 (that reduce but do not abolish $11 \beta$-HSD1 expression) and mutations in a novel endoplasmic reticulum enzyme, hexose-6-phosphate dehydrogenase that generates NADPH thereby conferring reductase activity upon 11ß-HSD1 (19).

The prevalence of CRD in patients with PCOS is unknown but milder abnormalities in the activity of 11ß-HSD1 have been reported in some PCOS cohorts (20).

\section{Obesity, insulin resistance and the metabolic syndrome}

The link between central or visceral adiposity and insulin resistance and premature mortality from cardiovascular disease has focussed attention on identifying factors that regulate fat distribution in addition to absolute fat mass. Patients with Cushing's syndrome develop florid, but reversible insulin resistance and central obesity in the setting of circulating glucocorticoid excess, but circulating cortisol concentrations are invariably normal in obesity (21). 11ß-HSD1 is expressed in abundance in adipose tissue, specifically omental fat, where it acts as a reductase generating cortisol locally and facilitating glucocorticoid-induced adipocyte differentiation $(4,22)$. 'Cushing's disease of the omentum', mediated via the autocrine expression of 11ß-HSD1, may explain the propensity of an individual to develop a central obese phenotype, an hypothesis that is supported through the phenotype of transgenic mice with targeted overexpression of $11 \beta-H S D 1$ in adipose tissue (23). In the liver $11 \beta$-HSD1 also serves an important autocrine role by regulating glucocorticoidinduced hepatic gluconeogenesis. Thus mice lacking $11 \beta$-HSD1 resist hyperglycaemia following stress and over-feeding and show reduced levels of expression of gluconeogenic enzymes (e.g. phosphoenolpyruvate carboxykinase) (24). By promoting adipocyte differentiation and hepatic glucose output it is easy to envisage how 11 $\beta$-HSD1 has become a novel therapeutic target in the treatment of metabolic syndrome. To support this concept selective inhibitors of 11ß-HSD1 have been developed, that unlike the liquorice derivatives (glycyrrhetinic acid, carbenoxolone) have no inhibitory action upon 11ß-HSD2. Preliminary and as yet short-term animal experiments indicate a beneficial effect of these arylsulphonamides upon glucose tolerance (25).

It seems unlikely, however, that a primary overexpression of $11 \beta$-HSD1 is a cause of central obesity. The data are conflicting but clinical studies suggest global inhibition, not stimulation, of $11 \beta$-HSD 1 activity in obesity. THF + allo-THF:THE ratios are slightly reduced in obese subjects as are circulating cortisol concentrations following an oral bolus of cortisone. Furthermore, expression analyses conducted on both subcutaneous and omental fat biopsies show a trend (at least in our studies) for reduced 11ß-HSD1 mRNA and activity with increasing body mass index (BMI) (26), findings that are reversible with weight loss. It is important to recognise the opposing effects of cortisol upon pre-adipocyte proliferation (inhibitory) and differentiation (stimulatory) and at an autocrine level $11 \beta$-HSD1 plays a regulatory role in both of these processes (Fig. 3). It should perhaps be regarded as an important protective rather than pathogenetic mechanism with inhibition of activity with increasing BMI (and thus reduced adipocyte differentiation and hepatic glucose output) serving to attenuate the deleterious consequences of obesity upon glucose tolerance. Human translational studies are now required utilising the selective 11 $\beta$-HSD1 inhibitors to fully define the role of this enzyme in human obesity.

\section{Other diseases}

The recent identification of $11 \beta$-HSD1 within osteoblasts has implications for the development of both age-related and glucocorticoid-induced osteoporosis (27). 11ß-HSD1 expression in bone increases with advancing age and is also positively regulated by proinflammatory cytokines including tumour necrosis factor- $\alpha$ and interleukin-1 (28, 29). Recent studies 


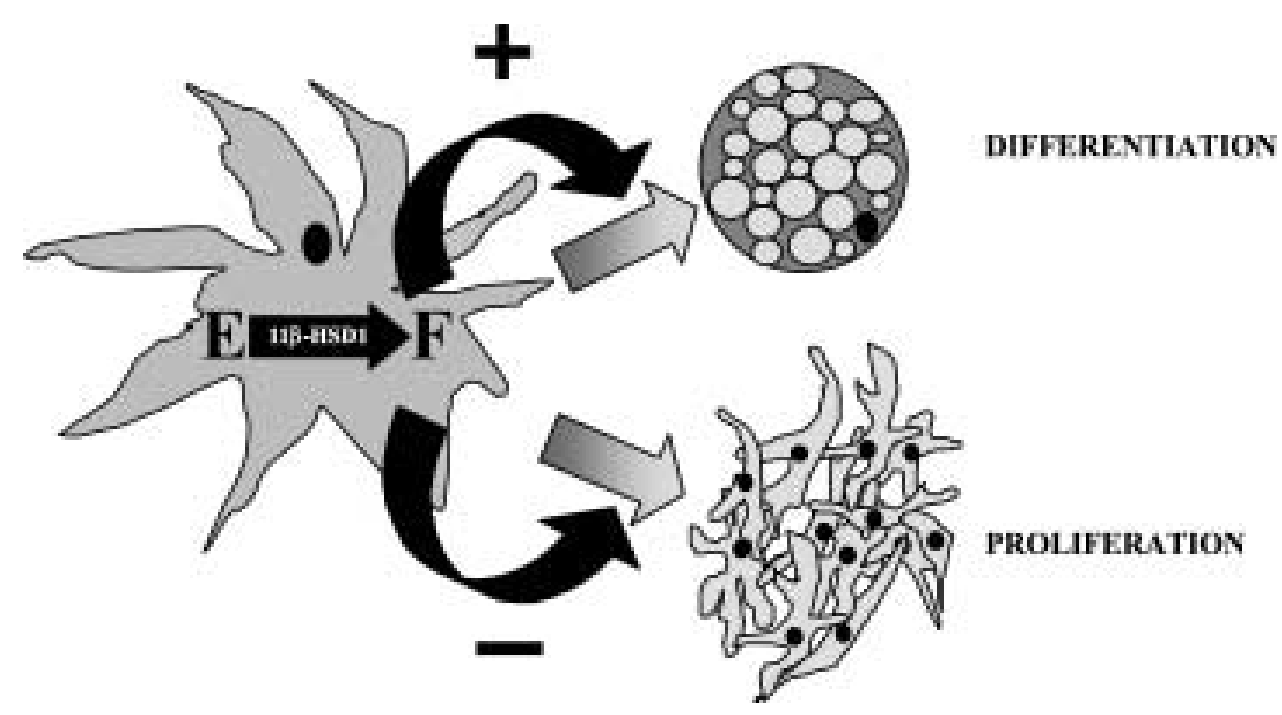

Figure 3 Proposed model for the role of $11 \beta-H S D 1$ in regulating adipose stromal cell proliferation and adipocyte differentiation in human adipose tissue. The net effect of increased expression in whole adipose tissue would be to reduce preadipocyte proliferation whilst at the same time stimulating adipocyte differentiation.

also highlight a predictive role for 11ß-HSD1 in the development of glucocorticoid-induced osteoporosis individuals with the highest levels of $11 \beta$-HSD1 had the greatest deleterious effects of glucocorticoids upon the skeleton as measured by markers of bone formation.

Finally, and perhaps of some surprise for a sodium transporting epithelial tissue, the ciliary body of the eye expresses an abundant amount of $11 \beta$-HSD1 but no $11 \beta$-HSD2 (30). Here clinical data support the concept of local generation of cortisol within this intraocular tissue that serves to stimulate epithelial sodium transport and the production of intraocular fluid. Systemic inhibition of $11 \beta$-HSD1 is associated with a reduction in intraocular pressure, raising the intriguing possibility that topical inhibition of $11 \beta$-HSD1 within the eye might represent a novel approach to treat patients with glaucoma.

\section{Summary}

$11 \beta$-HSDs play a pivotal role in the metabolism of cortisol, tightly controlling the exact concentration of cortisol that is available to bind to the GR (11ßHSD1) yet simultaneously protecting the MR from illicit occupation by cortisol (11 $\beta$-HSD2). The two isoforms identified to date interconvert cortisol and cortisone, type 1 acting principally as a reductase in vivo to generate cortisol and type 2 acting exclusively as a dehydrogenase to inactivate cortisol to cortisone. Inhibition of $11 \beta$-HSD2 underpins the mineralocorticoid hypertension induced by liquorice consumption and carbenoxolone therapy. Defects in the HSD11B2 gene are responsible for an inherited form of hypertension, AME, and the close relationship between genotype and phenotype in this condition raises the possibility that milder forms of AME or polymorphisms within the HSD11B2 gene may be implicated in the pathogenesis of essential hypertension. Conversely, CRD is an inherited form of PCOS explained by mutations in the HSD11B1 gene and a novel endoplasmic reticulumspecific re-dox enzyme, H6PDH. 11 $\beta$-HSD1 appears to be intricately involved in insulin resistant states such as central obesity, and may also be implicated in the pathogenesis of osteoporosis and glaucoma. Importantly, 'tissue-specific Cushing's syndrome' mediated through aberrant expression of the 11ß-HSD isozymes has uncovered novel therapeutic targets in the future treatment of common medical diseases.

\section{Acknowledgements}

It was a great honour to deliver the 2003 European Journal of Endocrinology Prize Lecture and the author wishes to thank everyone who made this possible. He extends his warmest thanks to two mentors, Christopher Edwards and Michael Sheppard and to all individuals associated with his research group over the last 15 years. Particular thanks are made to the invaluable contributions of Iwona Bujalska, Mark Cooper, Nicole Draper, Gareth Lavery, Si Rauz, Jeremy Tomlinson, Elizabeth Walker and his co-investigator Martin Hewison.

\section{References}

1 Lakshmi V \& Monder C. Purification and characterization of the corticosteroid 11 beta-dehydrogenase component of the rat liver 11 beta-hydroxysteroid dehydrogenase complex. Endocrinology 1988123 2390-2398. 
2 Ricketts ML, Verhaeg JM, Bujalska I, Howie AJ, Rainey WE \& Stewart PM. Immunohistochemical localization of type 1 11 beta-hydroxysteroid dehydrogenase in human tissues. Journal of Clinical Endocrinology and Metabolism $1998 \mathbf{8 3}$ 1325-1335.

3 Jamieson PM, Walker BR, Chapman KE, Andrew R, Rossiter S \& Seckl JR. 11 Beta-hydroxysteroid dehydrogenase type 1 is a predominant 11 beta-reductase in the intact perfused rat liver. Journal of Endocrinology $2000 \mathbf{1 6 5} 685-692$.

4 Bujalska IJ, Kumar S \& Stewart PM. Does central obesity reflect 'Cushing's disease of the omentum'? Lancet $1997 \mathbf{3 4 9}$ 1210-1213.

5 Shimojo M, Ricketts ML, Petrelli MD, Moradi P, Johnson GD, Bradwell AR et al. Immunodetection of 11 beta-hydroxysteroid dehydrogenase type 2 in human mineralocorticoid target tissues: evidence for nuclear localization. Endocrinology $1997 \mathbf{1 3 8}$ $1305-1311$.

6 Condon J, Gosden C, Gardener D, Nickson P, Hewison M, Howie AJ et al. Expression of type 21 beta-hydroxysteroid dehydrogenase and corticosteroid hormone receptors in early human fetal life. Journal of Clinical Endocrinology and Metabolism $1998 \mathbf{8 3}$ 4490-4497.

7 Palermo M, Shackleton CH, Mantero F \& Stewart PM. Urinary free cortisone and the assessment of 11 beta-hydroxysteroid dehydrogenase activity in man. Clinical Endocrinology 199645 605-611.

8 Ferrari P, Lovati E \& Frey FJ. The role of the 11 beta-hydroxysteroid dehydrogenase type 2 in human hypertension. Journal of Hypertension $2000 \mathbf{1 8} 241-248$.

9 White PC, Mune T \& Agarwal AK. 11 Beta-hydroxysteroid dehydrogenase and the syndrome of apparent mineralocorticoid excess. Endocrine Reviews 199718 135-156.

10 Nunez BS, Rogerson FM, Mune T, Igarashi Y, Nakagawa Y, Phillipov $\mathrm{G}$ et al. Mutants of 11 beta-hydroxysteroid dehydrogenase (11-HSD2) with partial activity: improved correlations between genotype and biochemical phenotype in apparent mineralocorticoid excess. Hypertension $199934638-642$.

11 Li A, Li KX, Marui S, Krozowski ZS, Batista MC, Whorwood CB et al. Apparent mineralocorticoid excess in a Brazilian kindred: hypertension in the heterozygote state. Journal of Hypertension $1997151397-1402$.

12 Agarwal AK, Giacchetti G, Lavery G, Nikkila H, Palermo M, Ricketts $\mathrm{M}$ et al. CA-repeat polymorphism in intron 1 of HSD11B2: effects on gene expression and salt sensitivity. Hypertension 200036 187-194.

13 Lovati E, Ferrari P, Dick B, Jostarndt K, Frey BM, Frey FJ et al. Molecular basis of human salt sensitivity: the role of the 11beta-hydroxysteroid dehydrogenase type 2. Journal of Clinical Endocrinology and Metabolism 199984 3745-3749.

14 Stewart PM, Wallace AM, Valentino R, Burt D, Shackleton CH \& Edwards CR. Mineralocorticoid activity of liquorice: 11-betahydroxysteroid dehydrogenase deficiency comes of age. Lancet $19872821-824$.

15 Ulick S, Wang JZ, Blumenfeld JD \& Pickering TG. Cortisol inactivation overload: a mechanism of mineralocorticoid hypertension in the ectopic adrenocorticotropin syndrome [see Comments]. Journal of Clinical Endocrinology and Metabolism $1992 \mathbf{7 4}$ 963-967.

16 Jamieson A, Wallace AM, Andrew R, Nunez BS, Walker BR, Fraser $\mathrm{R}$ et al. Apparent cortisone reductase deficiency: a functional defect in 11beta-hydroxysteroid dehydrogenase type 1. Journal of Clinical Endocrinology and Metabolism $1999 \mathbf{8 4}$ 3570-3574.

17 Biason-Lauber A, Suter SL, Shackleton CH \& Zachmann M. Apparent cortisone reductase deficiency: a rare cause of hyperandrogenemia and hypercortisolism. Hormone Research $200053260-266$.

18 Nordenstrom A, Marcus C, Axelson M, Wedell A \& Ritzen EM. Failure of cortisone acetate treatment in congenital adrenal hyperplasia because of defective 11beta-hydroxysteroid dehydrogenase reductase activity. Journal of Clinical Endocrinology and Metabolism 199984 1210-1213.

19 Draper N, Walker EA, Bujalska IJ, Tomlinson JW, Chalder SM, Arlt W et al. Mutations in the genes encoding $11 \beta$-hydroxysteroid dehydrogenase type 1 and hexose-6-phosphate dehydrogenase interact to cause cortisone reductase deficiency. Nature Genetics 200334 434-439.

20 Rodin A, Thakkar H, Taylor N \& Clayton R. Hyperandrogenism in polycystic ovary syndrome. Evidence of dysregulation of 11 betahydroxysteroid dehydrogenase. New England Journal of Medicine $1994330460-465$.

21 Fraser R, Ingram MC, Anderson NH, Morrison C, Davies E \& Connell JM. Cortisol effects on body mass, blood pressure, and cholesterol in the general population. Hypertension 199933 1364-1368.

22 Bujalska IJ, Kumar S, Hewison M \& Stewart PM. Differentiation of adipose stromal cells: the roles of glucocorticoids and 11betahydroxysteroid dehydrogenase. Endocrinology $1999 \quad 140$ 3188-3196.

23 Masuzaki H, Paterson J, Shinyama H, Morton NM, Mullins JJ, Seckl JR et al. A transgenic model of visceral obesity and the metabolic syndrome. Science 2001294 2166-2170.

24 Kotelevtsev Y, Holmes MC, Burchell A, Houston PM, Schmoll D, Jamieson $\mathrm{P}$ et al. 11Beta-hydroxysteroid dehydrogenase type 1 knockout mice show attenuated glucocorticoid-inducible responses and resist hyperglycemia on obesity or stress. PNAS $19979414924-14929$.

25 Alberts P, Engblom L, Edling N, Forsgren M, Klingstrom G, Larsson C et al. Selective inhibition of 11beta-hydroxysteroid dehydrogenase type 1 decreases blood glucose concentrations in hyperglycaemic mice. Diabetologia $2002 \mathbf{4 5} 1528-1532$.

26 Tomlinson JW, Sinha B, Bujalska I, Hewison M \& Stewart PM. Expression of 11beta-hydroxysteroid dehydrogenase type 1 in adipose tissue is not increased in human obesity. Journal of Clinical Endocrinology and Metabolism 200287 5630-5635.

27 Cooper MS, Walker EA, Bland R, Fraser WD, Hewison M \& Stewart PM. Expression and functional consequences of 11 betahydroxysteroid dehydrogenase activity in human bone. Bone 200027 375-381.

28 Cooper MS, Bujalska I, Rabbitt E, Walker EA, Bland R, Sheppard MC et al. Modulation of 11 beta-hydroxysteroid dehydrogenase isozymes by proinflammatory cytokines in osteoblasts: an autocrine switch from glucocorticoid inactivation to activation. Journal of Bone and Mineral Research 200116 1037-1044.

29 Cooper MS, Rabbitt EH, Goddard PE, Bartlett WA, Hewison M \& Stewart PM. Osteoblastic 11beta-hydroxysteroid dehydrogenase type 1 activity increases with age and glucocorticoid exposure. Journal of Bone and Mineral Research 200217 979-986.

30 Rauz S, Walker EA, Shackleton CH, Hewison M, Murray PI \& Stewart PM. Expression and putative role of 11 beta-hydroxysteroid dehydrogenase isozymes within the human eye. Investigative Ophthalmology and Visual Science $2001 \quad \mathbf{4 2}$ 2037-2042.

Received 19 May 2003

Accepted 20 May 2003 